\title{
İnşaat Yıkıntı Atıklarının Zemin İyileştirmesinde Kullanılabilirliği
}

\author{
İsa Vural \\ * Sakarya Üniversitesi, Teknoloji Fakültesi, İnşaat Mühendisliği Bölümü, Türkiye, ivural@ sakarya.edu.tr, \\ Araştırma Makalesi \\ Geliş Tarihi: 26.06.2018 \\ Kabul Tarihi: 20.09.2018
}

$\ddot{O} \mathbf{z}$

Zeminlerin mühendislik özelliklerinin yetersiz olduğu durumlarda zemin iyileştirerek mühendislik özellikleri arttırılabilmektedir. Zemin iyileştirme çalışmalarında kireç, çimento, uçucu kül vb. birçok yöntem kullanılmaktadır. Zemin iyileştirmelerinde zeminin mevcut mühendislik özellikleri ve iyileştirme maliyetleri önemli parametrelerdir. Bu çalışmada, deprem bölgelerinde ciddi çevre sorunu haline gelen, şehirlerde görüntü kirliliği yaratan ve yaşam konforunu bozan deprem yıkıntı atıklarının zemin iyileştirmesinde kullanılması amaçlanmıştır. Bu amaçla, Sakarya da 1999 yılı depremlerinde yıkılan binalara ait yıkıntı atıkları ile laboratuar ortamında zemin iyileştirmesi yapılarak bu zeminlerin CBR değerleri belirlenmiştir. Çalışmada, inşaat yıkıntı atığı, kireç ve kaolin karıştırılarak bu karışımların 1, 7 ve 28 günlük CBR değerleri ölçülmüştür. İyileştirilecek zemin örneği olarak şişme potansiyeli en yüksek olan kaolen kili kullanılmıştır. Karışımlarda kireç oranı \%0 referans, $\% 5$ ve $\% 8$ seçilirken, inşaat atığı oranı $\% 0$ referans ile $\% 23$ arasında, kaolin ise $\% 0$ referans ve $\% 72$ ile $\% 100$ arasında seçilmiştir. Karışımlarda birinci, yedinci ve yirmi sekizinci gün için en düşük CBR değerleri sırasıyla 26.3, 28.65 ve 33.13 olarak $\% 3$ Y 1 kıntı atığı, \%5 Kireç ve \%92 Kaolin kullanıldığında, en yüksek CBR değeri ise 33.52, 34.70 ve 34.95 ile \%23 yıkıntı atığı, \%5 kireç ve \%72 kaolin kullanıldığında elde edilmiştir.

Anahtar Kelimeler: İnşaat yıkıntı atığı, Zemin mekaniği, Zeminleri iyileştirilmesi

\section{Utilization of Construction Demolition Waste in Soil Improvement}

\author{
İsa Vural \\ * Sakarya University, Faculty of Technology, Department Of Civil Engineering, Turkey, ivural@ sakarya.edu.tr
}

\begin{abstract}
In the cases when the engineering properties of the soils are insufficient, engineering properties can be increased by improving the soil. In the soil improvement studies, various methods such as lime, cement, fly-ash etc., are employed. The available engineering properties and the cost of improvement are important parameters in the soil improvement. In this study, it was aimed to utilise earthquake construction waste, which has become a serious environmental problem in the earthquake zones, causes visual pollution in the cities and ruins the living comfort, in soil improvement. For this purpose, the CBR values of these soils were determined by carrying out soil improvements with the construction waste of the buildings collapsed in the 1999 earthquake in Sakarya in the laboratory environment. In the study, the CBR values of 1, 7, and 28 days of these mixtures were measured by mixing the construction waste, lime and kaolin. As the sample of the soil to be improved, kaolin clay which has the highest potential to swell was used. While the lime ratio in the mixtures was selected as $0 \%$ reference, $5 \%$ and $8 \%$, the construction waste ratio was selected between $0 \%$ reference and $23 \%$, and kaolin was selected as $0 \%$ reference and between $72 \%$ and $100 \%$. When 3\% Construction waste, 5\% Lime and 92\% Kaolin were used in the mixtures, the lowest CBR values were obtained as 26.3, 28.65 and 33.13 for the first, seventh and twenty-eighth days, respectively, and when $23 \%$ construction waste, $5 \%$ lime and $72 \%$ kaolin were used, the highest CBR values were obtained as 33.52, 34.70 and 34.95, respectively.
\end{abstract}

Keywords: Construction demolition waste, Soil mechanics, Soil stabilization.

\section{GİRIŞ}

Kaynaklarımızın sınırlı olduğu dünyada enerji tüketiminin azaltılması inşaat sektöründe de önemli bir amaçtır. Atık ürünlerin depolanması veya doğaya terk edilmesi diğer alanlarda olduğu gibi inşaat sektöründe de önemli sorunlara neden olmakta, çevreyi ve insan sağlığını tehdit eden sorunlara dönüşmektedir. Tüm sektörlerde olduğu gibi inşaat sektöründe de bu sorunları azaltabilmek için atık malzeme ve yan ürünlerinin kullanımını arttırıp kısıtlı olan doğal malzemelerin kullanımını azaltmak en önemli amaçlardan biri haline gelmiştir. Diğer taraftan, atık ürünlerin uygun şartlarda depolanması çevresel problemleri de azaltacaktır. Atık malzemeler ile oluşan çevre kirliliği de günümüzün 
önemli sorunlarından birini oluşturmaktadır. $\mathrm{Bu}$ nedenle inşaat sektörü açısından atık malzemelerin oluşturacağ 1 kirliliği azaltmak amacı ile bu malzemelerin farklı alanlarda kullanılabilirliği ile ilgili birçok çalışma yapılmaktadır. Yapılan araştırmalarda, atık asfalt (reclaimed asphalt pavement (RAP) aggregate), çimento tozu (CBPD), cüruf, eski araba lastiği, uçucu kül gibi atık malzemelerin zeminlerin iyileştirilmesinde katkı malzemesi olarak kullanılması durumunda zeminin mühendislik özelliklerinin iyileştirilebileceği görülmüştür. Ancak, kayma mukavemetini arttırmak, geçirimlilik ve suya isteği azaltmak, hacim değişimini en aza indirmek gibi amaçlarla yapılan çalışmalarda kullanılan atık maddelerin endüstri yan ürünleri olması ve jeolojik ortamın kirlenmesine yol açması bu atık endüstri ürünlerinin kullanılabilirliğini olumsuz etkilediği görülmüştür. Yapılan çalışmalarda, incelenen birçok malzeme ve atıklardan sadece birkaçının zemin iyileştirilmesinde kullanılabileceği belirtilmektedir. Bunlar zeminin iyileştirilmesindeki etkinlikleri yanında, ucuz olmaları ve ihtiyaç duyulduğunda kolayca bulunabilme özeliğine göre çimento, bitüm, kireç, fosforik asit, kalsiyum bileşikleri, reçine ve polimerler ile çok değerlikli iyon içeren maddelerdir [1]. Zemin stabilizayon yöntemleri arasında katk1 maddeleri ile stabilizasyon en çok uygulanan yöntemlerinden biridir. Stabilizasyonda katkı maddeleri ile iyileştirme, problemli zemin yapısına bir veya daha fazla bileşiğin katılmasıyla ilgilidir. Çimento, cüruf, uçucu kül, kireç veya geri dönüştürülmüş katkı maddeleri zeminlerin stabilizasyonu için etkin bir şekilde kullanılmaktadır. Zemin stabilizasyonunda amaçlar, tane boyutunun arttırılması, mukavemetin arttırılması, plastisite indeksinin düşürülmesi ve büzülme-şişme potansiyelinin azaltılması olarak hedeflenmektedir [2-8].

Türkiyede özellikle şehirlerdeki gece kondu alanları, depremde yıkılmış binlardan oluşan alanlar ile ağır hasar görmüş binların olduğu alanlarda kentsel dönüşüm yasası (6303 sayılı yasa) ile birlikte mevcut yapıların yıkılması ve çeşitli mimari çalışmaların modernizasyonu gibi etkenler büyük miktarda inşaat yıkıntı atığı oluşumuna neden olmaktadır. Çok büyük miktarlara ulaşan ve özellikle çevre kirliliği, görüntü kirliliği vb. şehir dokusuna zarar veren yıkıntı atıkları büyük bir soruna dönüşmüştür. İnşaat alanlarında dolgu yapmak için bu atıklardan düşük miktarlarda kullanılmakta, ancak açıkta kalan milyonlarca ton atık yetersiz depolama alanlarına yığılmaya çalışılmaktadır. Ancak büyük miktarlardaki bu inşaat yıkıntı atıkları çevreye büyük zarar vermektedir. Diğer taraftan iyileştirme amacı ile doğal kaynakların kullanılması da olumsuz bir etken olarak karşımıza çıkmaktadır [9]. Dünyada birçok ülkede, yüksek firın cürufu gibi endüstriyel yan ürünlerin yasadışı veya çevresel açıdan güvensiz bir şekilde elden çıkarılması çevre sağlığı açısından dünyada giderek artan bir endişe oluşturmakta ve araştırmacıları bu sorunlara sürdürülebilir çözümler bulmaya itmektedir. $\mathrm{Bu}$ nedenle araştırmacılar, zemin stabilizasyonu için alternatif malzemelerin kullanımı ile ilgili olarak çalışmalarına devam etmektedir [10-12]. Yapılan araştırmalara göre yıkıntı atıklarının karbon salınımını arttırarak çevreye zarar vermeside bir başka problem olarak ortaya çıkmaktadır [13]. Bu nedenle Avrupa'daki bazı gelişmiş ülkelerde karbon ayak izini azaltmak ve zeminlerin taşıma kapasitesini arttırmak amacı ile yıkıntı atıklarının tekrar kullanımına yönelik çalışmalar artmış olup ayrıca teşvik edilmektedir [1418].Avustralya gibi gelişmiş ülkelerde işlenmiş ve yeniden kullanılabilir şekilde sınıflandırılmış inşaat atıkları ton başına 8-10 AUD'a mal olmaktadır. Avrupa Birliği'nin bu ürünlerin yeniden kullanımı gibi çevreci inşaat uygulamaları için teşvikleri bulunmaktadır. [19]. Zeminlerin stabilizasyonunda stabilizör seçimi için, zemin cinsi, stabilizasyonun amacı (stabilite artışı, kaplama kalınlığının azalması, vb.), zeminin hangi özelliğinin iyileştirilecği, maliyeti ve elde edilme kolaylığı gibi hususlar göz önünde tutulmaktadır. Bu nedenle literatürde bölgesel şartlar altında kullanım yerlerine göre stabilizatöre bağlı olarak değişen birçok zemin iyileştirme yöntemi mevcuttur. $\mathrm{Bu}$ yöntemler genel olarak;

$\begin{array}{cl}\circ & \text { Kireçle Stabilizasyon } \\ \circ & \text { Çimento ile Stabilizasyon } \\ \circ & \text { Bitümle Stabilizasyon } \\ \circ & \text { Kireç- Baca Külü ile Stabilizasyon } \\ \circ & \text { Cüruf Katkısı } \\ \circ & \text { Uçucu Kül Katkısı } \\ \circ & \text { Eski Kamyon Lastiği Katkısı } \\ \circ & \text { Uçucu Kül ve Çimento Katkısı } \\ \circ & \text { Kireç ve Çimento Katkısı'dır. }\end{array}$

$\mathrm{Bu}$ yöntemlerden, kireç ve çimento katkısı ile zeminlerin stabilizasyonunu amacıyla (Tüdeş, 1996) Doğu Karadeniz bölgesi zeminlerin fiziksel özelliklerini laboratuar deneyleri ile, mineralojik özelliklerini Differantial Thermal Analysis (DTA) ve X 1şını (XRD) deneyleri ile belirlemiştir. Seçilen zeminler değişik oranlarda çimento ve kireç ilave edildikten sonra standart bir enerji ile sıkıştırılmış ve kayma direnci parametreleri belirlenmiştir. Çimento ve kireç ilave edilmeyen referans numunelerin kayma direnci değerleri ile karşılaştırılmıştır. Sonuç olarak, kireç ve çimentonun zeminin özellikle $\% 5$ 'i ile $\% 15$ 'i arasındaki katkı oranlarının optimum katkı maddesi oranı olduğu ve katkı oranı artışının her karışımda stabilizasyonu doğrusal olarak arttırmadığını göstermiştir [20].

Kentsel dönüşüm yasasıyla şehir içinde bulunan gece kondu alanlar1, depremde yıkılmış, depremde ağır hasar görmüş vb. nitelikte olan binaların yıkılması ile oluşan inşaat atıklarının çevre kirliliği oluşturmaması yada bu etkinin minimize edilmesine katkı sağlamak amacıyla yapılan bu çalışmada; zemin stabilizasyonunda geri dönüştürülmüş inşaat yıkıntı atıklarının kullanılması deneysel olarak incelenmiş ve analizler yapılarak değerlendirilmiştir. Bu amaçla, deneysel çalışmalarda doğal zemin numunesi olarak kabul edilen kaolen kiline değişik oranlarda inşaat yıkıntı atığ katılarak, farklı karışımlarda numuneler hazırlanmıştır. Hazırlanan numuneler üzerinde CBR taşıma gücü analizleri yapılarak taşıma gücü zayıf zeminlerin inşaat yıkıntı atıkları ile iyileştirilebilirliği laboratuar ortamında yapılan deneylerle incelenmiştir. 


\section{MALZEME VE METOD}

\subsection{MALZEME}

Karışımlarda doğal zemin zemin numunesi olarak kaole kili kullanılmıtır.Kullanılan kaolen kili ve kireç'in kimyasal içeriği Tablo 1.'de verilmiştir. Deney aşamalarında kullanılan kil, kireç ve inşaat yıkıntı atığının ortalama özgül ağırlık değerleride Tablo 2.'de verilmiştir [21].
Çalışmalada Kireçtaşı (kalsiyum karbonat) kalsinasyonlarında üretmek için kireç kullanılmaktadır.

$\mathrm{Bu}$ reaksiyonun kimyasal denklemi;

$\mathrm{CaCO}_{3}+$ heat $\rightarrow \mathrm{CaO}+\mathrm{CO}_{2}$

Bu reaksiyonda aşırı sıcaklıktan kaçınılır, aksi halde reaktif olamaya "sönmüş kireç" ortaya çıkar. Çalışmada kullanılan kirecin kimyasal içeriği Tablo 1.'de, özgül ağırlığı Tablo 2.'de verilmiştir.

Tablo1. Malzemelerin kimyasal bileşimleri

\begin{tabular}{|l|c|c|c|c|c|c|c|c|c|c|c|}
\hline \multicolumn{1}{|c|}{ Malzeme } & $\% \mathrm{SiO}_{2}$ & $\% \mathrm{Al}_{2} \mathrm{O}_{3}$ & $\% \mathrm{Fe}_{2} \mathrm{O}_{3}$ & $\% \mathrm{TiO}_{2}$ & $\% \mathrm{CaO}$ & $\% \mathrm{MgO}$ & $\% \mathrm{Na}_{2} \mathrm{O}$ & $\% \mathrm{~K}_{2} \mathrm{O}$ & $\% \mathrm{MnO}$ & $\% \mathrm{SO}_{3}$ & $\% \mathrm{~K} . \mathrm{K}$. \\
\hline Kaolen kili & 45.65 & 37.63 & 0.73 & 0.13 & 0.3 & 0.27 & 0.62 & 2.4 & - & - & 11.91 \\
\hline Kireç & 0.70 & 0.40 & 0.40 & 0.5 & 87 & 4.50 & - & - & - & 0.80 & 4 \\
\hline
\end{tabular}

KK: Kayıp oranı

Tablo 2. Malzemelerin özgül ağırlıkları

\begin{tabular}{|c|c|c|c|}
\hline Malzeme türü & İnşaat Yıkıntı Atığ & Kaolen Kili & Kireç \\
\hline $\mathrm{G}_{\mathrm{s}}$ & 2.51 & 2.58 & 2.41 \\
\hline
\end{tabular}

\subsection{Method}

$\mathrm{Bu}$ çalışmada, inşaat yıkıntı atıklarının zeminlerin stabilazyonunda kullanılabileceği deneysel olarak gösterilmiştir. Çalışmada, 8 farklı karışım hazırlanarak inşaat yıkıntı atığının kompaksiyon özellikleri incelenmiş ve kompaksiyon için optimum su muhtevası belirlenmiştir TS1900-1 (2006) [21]. Optimum su muhtevalarında sıkıştırılan bu karışımların taşıma gücü değerlerinin belirlenmesi amacıyla CBR deneyleri yapılarak elde edilen sonuçlar referans numune sonuçları ile karşılaştırılmıştır TS1900-2 (2006) [22]. Diğer taraftan, katkı maddelerinin kür süresine bağlı olarak muhtemel puzolanik aktivitenin ortaya çıkaracağı iyileşmeyi görebilmek amacıyla da numuneler farklı kür sürelerine maruz bırakılmış ve bu numuneler üzerinde de CBR deneyleri yapılarak sonuçlar çok yönlü değerlendirilmiştir.

\section{DENEYSEL ÇALIŞMALAR}

İnşaat yıkıntı atıklarının zemin stabilizasyonunda kullanılabilmesi amaciyla yapılan deneyler TS1500 (2000) [23], ASTM D4318 (2010) [24], TS1900-1 (2006) [21] ve TS1900-2 (2006) [22] standartlarına uygun olarak yapılmış ve elde edilen sonuçlar bu kapsamda değerlendirilmiştir.

\section{1. İnşaat Yıkıntı Atığı ve Kaolen Kilinin Özellikleri}

Deneylerde kullanılan malzemeler TS1500 (2000) [23] ve ASTM D4318 (2010) [24] göre sinıflandırılmıştır. Sinıflandırma deneyleri TS1900-1 (2006) [21] standartlarına göre yapılmıştır. Deney sonuçlarına göre Kaolen kilinin plastik limiti değeri 25.81, likit limit değeri 55.37 olarak belirlenmiş ve kaolin kilinin yüksek plastisiteli Kil $(\mathrm{CH})$ olduğu tespit edilmiştir (Şekil 1 ve Şekil 2).

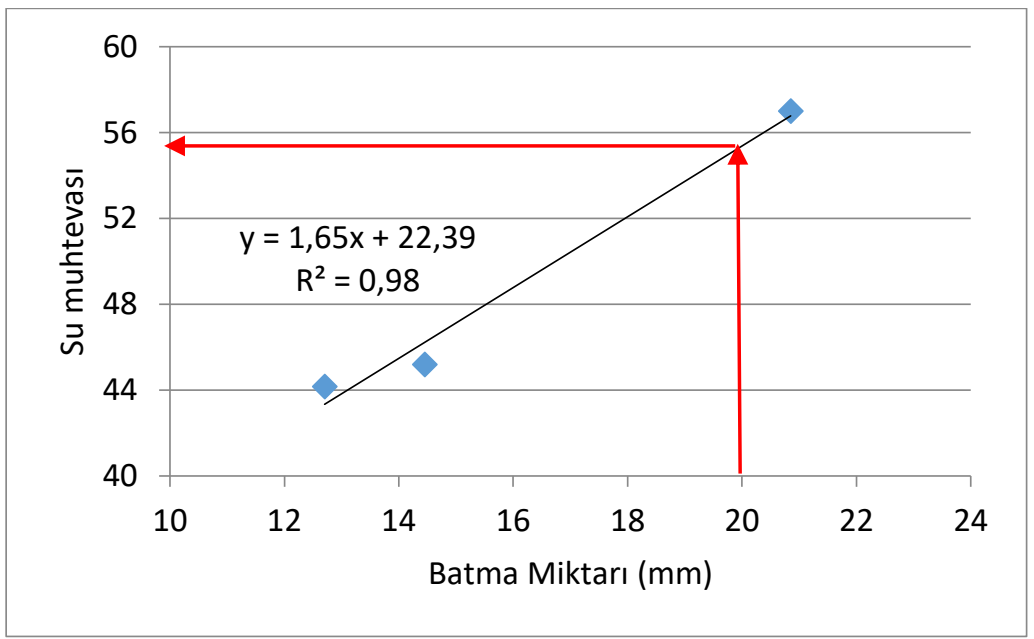

Şekil 1. Kaolen kili için Koni Penetrasyon deney sonucu 


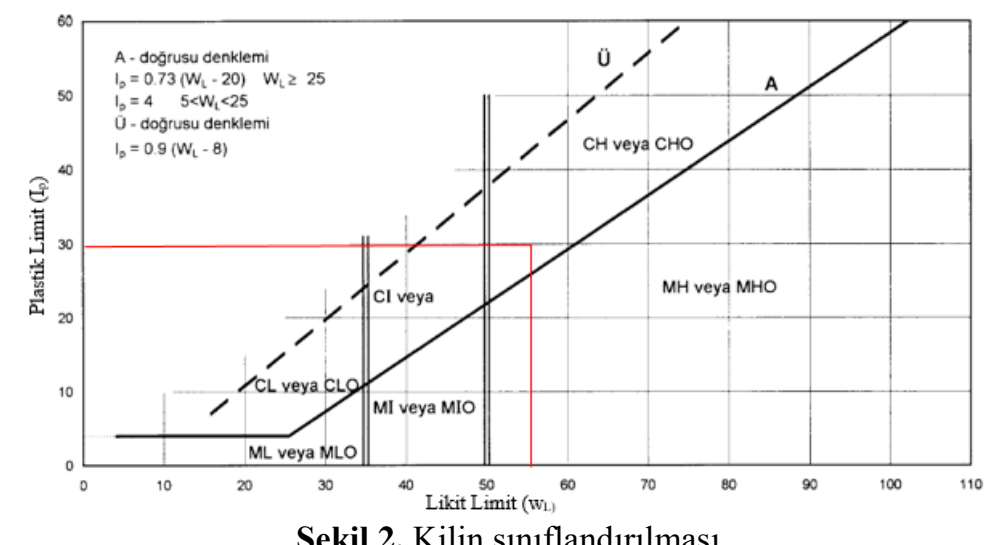

Şekil 2. Kilin sınıflandırılması.

\subsection{Standard Proktor Deneyi}

Standart proktor deneyi, bir zemin örneğinin maksimumu kuru birim hacim ağırlığa ulaştığı andaki optimum su içeriği ve maksimum kuru birim hacim ağırlık değerini deneysel olarak belirleyen bir laboratuar yöntemidir. [21]. Deney sonucu elde edilen veriler ile kuru birim hacim ağırlık ve su içeriğinin grafiksel ilişkisini ifade eden bir eğri elde edilir. $\mathrm{Bu}$ eğrinin tepe noktasına karşılık gelen su muhtevası optimum su içeriği ve birim hacim ağırlık değeride maksimum kuru birim hacim ağırlık değeri olarak kabul edilir.

$\mathrm{Bu}$ araştırmada kompaksiyon deneyleri aşamasında kireç oranı $\% 5$ te sabit tutularak inşaat yıkıntı atık oranı değişken olarak belirlenmiştir. Karışımlarda inşaat yıkıntı atığı ağırlık olarak $\% 3, \% 8, \% 13, \% 18$ ve $\% 23$ oranında arttırılarak oluşturulmuştur. Karışımlardaki bu artış kuru birim hacim ağırlıkta yükselmeye neden olmuştur.

\subsection{CBR Deneyleri}

Karayolu alt dolgularında kullanılacak sıkıştırma malzemesinin taşıma kapasitesini belirlemek için California Taşıam Gücü (CBR) deneyi TS1900-2'ye (2006) uygun olarak gerçekleştirilmiştir [22]. Bu deney yol yapımında kullanılan ve çeşitli koşulları içeren evrensel bir standarttır. $\mathrm{Bu}$ çalışmada, numuneler CBR testi için Standart Proktor deneyinde elde edilen optimum su içeriğinde sıkıştırılmıştır. Daha sonra CBR testi için üç adet numune hazırlanmış ve bu numuneler 1,7 ve 28 günlük kür işlemine tabi tutulmuştur. Kür işlemi sonrası CBR deneyine tabi tutulan bu numunelere ait dedey sonuçları Tablo 3.de görülmektedir.

Tablo 3. CBR test sonuçları ve numune detayları.

\begin{tabular}{|c|c|c|c|c|c|c|c|}
\hline \multirow{2}{*}{$\begin{array}{c}\text { Attk } \\
\%\end{array}$} & \multirow{2}{*}{$\begin{array}{c}\text { Kireç } \\
\%\end{array}$} & $\begin{array}{c}\text { Kaolen } \\
\text { Kili } \\
\%\end{array}$ & \multirow{2}{*}{$\begin{array}{c}\mathrm{w} \\
\%\end{array}$} & $\begin{array}{c}\rho_{\mathrm{k}} \\
\mathrm{kN} / \mathrm{m}^{3}\end{array}$ & 1 gün & 7 gün & 28 Gün \\
\hline 3 & 5 & 92 & 5 & 10.67 & 26.3 & 28.65 & 33.13 \\
\hline 8 & 5 & 87 & 16 & 11.35 & 28.65 & 29.75 & 34.25 \\
\hline 13 & 5 & 82 & 13 & 10.68 & 29.75 & 32.32 & 34.68 \\
\hline 18 & 8 & 77 & 13 & 10.68 & 31.525 & 32.83 & 34.93 \\
\hline 23 & 5 & 72 & 14 & 11.12 & 33.525 & 34.7 & 34.95 \\
\hline
\end{tabular}

Tablo 3. incelendiğinde inşaat yıkıntı atığının katkısı ile taşıma gücünde artış olduğu ve kür süresininde buna pozitif katkı yaptığı görülmektedir

\section{DENEYSEL SONUÇLARININ ANALİZI VE MODELLENMESI}

İnşaat yıkıntı atıklarının zeminin iyileştirilmesinde kullanılabilirliğinin araştırılması amacıyla yapılan bu çalışmada farklı kireç, kaolin ve yıkıntı atığı oranlarına göre zeminin CBR değerlerindeki değişimler incelenmiştir. CBR deneylerinin yapılabilmesi için laboratuar ortamında standart kompaksiyon deneyleri yapılmıştır. Deneyler sonucunda elde edilen verilerin anlamlılığını ve veriler arasındaki ilişkilerin belirlenebilmesi amacıyla istatistiksel analizler yapılmıştır.

Zeminin iyileştirilmesi için farklı oranlarda inşaat yıkıntı atığı. kireç ve kaolin karıştırılarak deney numuneleri hazırlanmıştır. $\mathrm{Bu}$ numuneler üzerinde kompaksiyon deneyleri yapılarak her bir karışımın su muhtevası. kuru birim hacim ağırlıkları ve bu su muhtevası ve kuru birim hacim ağırlık değerleri için aynı numunelerin birinci. yedinci ve yirmi sekizinci günlerdeki CBR değerleri ölçülmüştür. Deney sonuçlarının birbiri ile ilişkisi olup olmadığı ve ilişki var ise hangi düzeyde ilişkiler olduğunu belirleyebilmek amacıyla korelasyon analizi yapılmıştır (Tablo 4). 
Tablo 4. Korelasyon Değerleri

\begin{tabular}{|c|c|c|c|c|c|c|c|c|}
\hline & Atık & Kireç & Kaolen & Su muht. & $\begin{array}{c}\text { Kuru bir.hac. } \\
\text { ağır. }\end{array}$ & 1.gün & 7.gün & 28.gün \\
\hline Atık & 1.00 & 0.35 & $-1.00^{* *}$ & 0.21 & 0.18 & $0.99^{* *}$ & $0.98^{* *}$ & $0.90^{* *}$ \\
\hline Kireç & 0.35 & 1.00 & -0.35 & 0.03 & -0.03 & 0.32 & 0.27 & $0.40^{*}$ \\
\hline Kaolin & $-1.00^{* *}$ & -0.35 & 1.00 & -0.21 & -0.18 & $-.99^{* *}$ & $-0.98^{* *}$ & $-0.90^{* *}$ \\
\hline Su muhtevas1 & 0.21 & 0.03 & -0.21 & 1.00 & $0.79^{* *}$ & 0.22 & 0.20 & 0.25 \\
\hline Kuru bir.hac. ağır. & 0.18 & -0.03 & -0.18 & $0.79^{* *}$ & 1.00 & 0.23 & 0.14 & 0.34 \\
\hline 1.gün & $0.99^{* *}$ & 0.32 & $-0.99^{* *}$ & 0.22 & 0.23 & 1.00 & $0.97^{* *}$ & $0.91^{* *}$ \\
\hline 7.gün & $0.98^{* *}$ & 0.27 & $-0.98^{* *}$ & 0.20 & 0.14 & $0.97^{* *}$ & 1.00 & $0.89^{* *}$ \\
\hline 28.gün & $0.90^{* *}$ & $0.40^{*}$ & $-0.90^{* *}$ & 0.25 & 0.34 & $0.91^{* *}$ & $0.89^{* *}$ & 1.00 \\
\hline
\end{tabular}

**. Korelasyon 0.01 düzeyinde önemlidir. *. Korelasyon 0.05 düzeyinde önemlidir .

Tablo incelendiğinde. atık miktarı ile sırasıyla kireç miktarı, su muhtevası ve kuru birim hacim ağırlık arasında $0.35,0.21$ ve 0.18 ile pozitif yönde zayıf ilişkiler olduğu buna karşın atık miktarı ile birinci, yedinci ve yirmi sekizinci günlerdeki CBR arasında sirasiyla $0.99,0.98$ ve 0.90 ile pozitif yönde çok yüksek düzeyde ilişkiler olduğu görülmektedir. Kaolin miktarı ile CBR değerleri arasında negatif yönde çok yüksek ilişkiler olduğu buna karşın kireç miktarı ile CBR değerleri arasında ise pozitif yönde zayıf ilişkiler olduğu görülmektedir. Thyagaraj T, Zodinsanga [8] yaptığı araştırmada kireç katkısı ile stabilizayon konusunu incelemiş ve elde ettiği sonuçlara göre bu konuda ki pozitif ilişkiyi çalışmalarında ifade etmişlerdir.

\section{SONUÇLAR VE ÖNERİLER}

İnşaat yıkıntı atıklarının zemin iyileştirmede kullanılabilmesi amacıyla yapılan bu çalışmada, Sakarya da 1999 yılı depremlerinde yıkılan inşaat atıkları ile laboratuar ortamında CBR deneyleri yapılmıştır. Çalışmada, inşaat yıkıntı atığı, kireç ve kaolin karıştırılarak bu karışımların 1, 7 ve 28 günlük CBR değerleri ölçülmüştür. Çalışmada elde edilen sonuçlar aşağıda ifade edilmiştir. Bunlar;

- İyileştirilecek zemin örneği olarak şişme potansiyeli en yüksek olan kaolen kili kullanılmıştır.

- Karışımlarda kireç oranı $\% 0$ referans, $\% 5$ ve $\% 8$ seçilirken, inşaat atığ arasında, kaolin ise $\% 0$ referans ve $\% 72$ ile $\% 100$ arasında seçilmiştir.

- Karışımlarda birinci, yedinci ve yirmi sekizinci gün için en düşük CBR değerleri sırasıyla 26.3, 28.65 ve 33.13 olarak $\% 3$ yıkıntı atığı, \%5 Kireç ve \%92 Kaolin kullanıldığında elde edilmiştir.

- $\quad$ En yüksek CBR değerinin ise 33.52, 34.70 ve 34.95 ile \%23 yıkıntı atı̆̆ 1 , \%5 kireç ve \%72 kaolin kullanıldığında elde edilmiştir.

- Kaolen kilinin plastik limiti değeri 25.81, likit limit değeri 55.37 olarak belirlenmiş ve kaolin kilinin yüksek plastisiteli Kil $(\mathrm{CH})$ olduğu tespit edilmiştir.

- En yüksek kuru birim hacim ağırlık değerinin \%14 su muhtevasına sahip \%23 inşaat atığ1, \%5 lime ve \%72 Kaolin karışımında 11,12 kN/m³ olarak elde edilmiştir.
- En yüksek CBR değerlerinin de yine \%14 su muhtevasına sahip \%23 inşaat atığı, \%5 lime ve \%72 Kaolin karışımında elde edildiği tespit edilmiştir. $\mathrm{Bu}$ karışım için 1. gündeki $\mathrm{CBR}$ değerinin 33.525 olduğu, 7. gündeki CBR değerinin 34.7 olduğu ve 28 . gündeki CBR değerinin de 34.95 olduğu tespit edilmiştir.

- Atık miktarı ile birinci, yedinci ve yirmi sekizinci günlerdeki CBR arasında sırasıyla 0.99, 0.98 ve 0.90 ile pozitif yönde çok yüksek düzeyde ilişkiler olduğu görülmüştür.

- Kaolin miktarı ile birinci, yedinci ve yirmi sekizinci günlerdeki CBR değerleri arasında -0.99, -0.98, 0.90 ile negatif yönde çok yüksek ilişkiler olduğu görülmüştür.

- Kireç miktarı ile birinci, yedinci ve yirmi sekizinci günlerdeki CBR değerleri arasında 0.32, 0.27 ve 0.40 ile pozitif yönde zayıf ilişkiler olduğu görülmüştür.

Elde edilen tüm sonuçlar bir bütün olarak değerlendirildiğinde şehir ve çevre kirliliğine neden olan, depremde yıkılan, ağır hasar gören inşaat atıkları ile kentsel dönüşüm kapsamında yıkılan yapılara ait inşaat atıklarının zemin iyileştirmelerinde rahatlıkla kullanılabileceği tespit edilmiştir.

\section{REFERENCES}

[1] A. Önalp, İnşaat Mühendislerine Geoteknik Bilgisi, Cilt 2, K.T.Ü, Trabzon, 1983.

[2] B. R. P. Kumar and R. S. Sharma, "Effect of Fly Ash on Engineering Properties of Expansive Soils," Journal of Geotechnical and Geoenvironmental Engineering, vol. 130, no. 7, pp. 764-767, 2004

[3] A. A. Al-Rawas, A. Hago, and H. Al-Sarmi, "Effect of lime, cement and Sarooj (artificial pozzolan) on the swelling potential of an expansive soil from Oman," Building and Environment, vol. 40, no. 5, pp. 681687, 2005.

[4] Neeraja D, Rao Narsimha AV, "Use of certain admixtures in the construction of pavement on expansive clayey subgrade", Int. J. Eng. Sci. Technol., 2(11):61086114, 2010. 
[5] L. Yadu and R. Tripathi, "Effects of Granulated Blast Furnace Slag in the Engineering Behaviour of Stabilized Soft Soil," Procedia Engineering, vol. 51, pp. 125-131, 2013

[6] M. Khemissa and A. Mahamedi, "Cement and lime mixture stabilization of an expansive overconsolidated clay," Applied Clay Science, vol. 95, pp. 104-110, 2014.

[7] V. Ortega-López, J. M. Manso, I. I. Cuesta, and J. J. González, "The long-term accelerated expansion of various ladle-furnace basic slags and their soil-stabilization applications," Construction and Building Materials, vol. 68, pp. 455-464, 2014.

[8] T. Thyagaraj, S. M. Rao, P. S. Suresh, and U. Salini, "Laboratory Studies on Stabilization of an Expansive Soil by Lime Precipitation Technique," Journal of Materials in Civil Engineering, vol. 24, no. 8, pp. 1067-1075, 2012.

[9] U. Hasan, A. Chegenizadeh, M. A. Budihardjo, and H. Nikraz, "Experimental Evaluation of Construction Waste and Ground Granulated Blast Furnace Slag as Alternative Soil Stabilisers," Geotechnical and Geological Engineering, vol. 34, no. 6, pp. 1707-1722, 2016.

[10] M. H. Al-Malack, G. M. Abdullah, O. S. B. AlAmoudi, and A. A. Bukhari, "Stabilization of indigenous Saudi Arabian soils using fuel oil flyash," Journal of King Saud University - Engineering Sciences, vol. 28, no. 2, pp. 165-173, 2016.

[11] O. Amu, A. Fajobi, and S. Afekhuai, "Stabilizing Potential Of Cement-Fly Ash Mixture On Expansive Clay Soil," Journal of Technology and Education in Nigeria, vol. 12, no. 2, 2008.

[12] M. J. Mccarthy, L. J. Csetenyi, A. Sachdeva, and R. K. Dhir, "Engineering and durability properties of fly ash treated lime-stabilised sulphate-bearing soils," Engineering Geology, vol. 174, pp. 139-148, 2014.

[13] M. Limbachiya, M. S. Meddah, and Y. Ouchagour, "Use of recycled concrete aggregate in fly-ash concrete," Construction and Building Materials, 2011.

[14] Y. Kasai, "The Second International RILEM Symposium on demolition and reuse of concrete and masonry," Materials and Structures, vol. 22, no. 4, pp. 312 319, 1989.

[15] T. C. Hansen, "Recycled aggregates and recycled aggregate concrete second state-of-the-art report developments 1945-1985," Materials and Structures, vol. 19, no. 3, pp. 201-246, 1986.

[16] Khalaf F, DeVenny A, "Recycling of demolished masonry rubble as coarse aggregate in concrete: review", $J$. Mater. Civ. Eng., 16(4):331-340, doi:10.1061/(ASCE)08991561,16:4(331), 2004.

[17] C.-S. Poon and D. Chan, "The use of recycled aggregate in concrete in Hong Kong," Resources, Conservation and Recycling, vol. 50, no. 3, pp. 293-305, 2007.

[18] M. C. Rao, S. K. Bhattacharyya, and S. V. Barai, "Influence of field recycled coarse aggregate on properties of concrete," Materials and Structures, vol. 44, no. 1, pp. 205-220, Jun. 2010.

[19] http://www.environment.gov.au/about-us

[20] Tüdeş E., "Zeminlerin Kireç ve Çimento Katkısı ile Çözümü”, Karadeniz Teknik Üniversitesi, Yüksek Lisans Tezi, 161s, 1996.

[21] TS 1900-1, "Methods of testing soils for civil engineering purposes in the laboratory part 1:determination of physica properties", TSI, Ankara, [in Turkish], 2006.

[22] TS 1900-2, "Methods of testing soils for civil engineering purposes in the

laboratory - Part 2: Determination of mechanical properties", TSI, Ankara, [in Turkish], 2006.

[23] TS 1500, "Classification of Soil For Civil Engineering Purposes”, TSI, Ankara, pp. 25-57, [in Turkish], 2000 .

[24] ASTM D4318, "Standard Test Methods for Liquid Limit, Plastic Limit, and Plasticity Index of Soils”, 2008. 